\title{
Dreams and realities of school tracking and vocational education
}

\author{
Mahmut Ozer ${ }^{1}$ \& Matjaž Perc (iD $2,3,4 \bowtie$
}

\begin{abstract}
School tracking has been introduced as a means to provide skills the labor market demands, and as such has been in place for several decades in most Organisation for Economic Cooperation and Development (OECD) countries. The time is thus ripe for a critical review of the effects this has had on the equalities in education and opportunities later in life, and on the quality of vocational education in general. A synthesis of the existing literature reveals gaping holes between the dreams of superior vocational education and training that educational tracking ought to deliver, and the realities of lost opportunities and facilitated inequalities, especially in students with poor socioeconomic background, weak social capital, and sparse social networks. This is all the more true the sooner educational tracking comes into effect. While most OECD countries will start tracking students aged 15 or 16, some countries, such as Germany, will start doing this as early as age 10. Our review shows that this can have catastrophic consequences for students that for various reasons perform poorly early on, as they are indeed unable to recover due to the Matthew effect and preferential attachment in social networks, both of which punish false starts in life and reward first movers. To remedy the situation, we propose educational tracking be held off until later in life, and even then be undertaken with flexibility and late bloomers in mind. We also propose to restructure vocational education by decreasing the degree of curriculum differentiation, by allowing broader vocational education curricula, and by decreasing the number of training occupations in order to account for the changing labor market dynamics.
\end{abstract}

\section{Introduction}

ducation systems around the world involve a general comprehensive education until specific age levels, following which students are tracked into different school types. Tracking in education, also known as ability grouping, sorting, or differentiation, is used for purposive grouping of students in classrooms of the same school or in different types of schools. This disintegration or the placement of students has a hierarchical structure, which is based on students' academic performance and/or ability tests (Brunello, 2004). The tracking between school types leads to the physical decomposition of students in different schools and creates major differences in curricula. The scale of the curriculum differentiation has a critical

\footnotetext{
${ }^{1}$ Ministry of National Education, Ankara 06420, Turkey. ${ }^{2}$ Faculty of Natural Sciences and Mathematics, University of Maribor, 2000 Maribor, Slovenia.

${ }^{3}$ Complexity Science Hub Vienna, 1080 Vienna, Austria. ${ }^{4}$ Department of Medical Research, China Medical University Hospital, China Medical University,

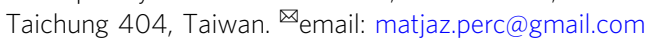


role in tracking (Reichelt et al., 2019). Although the tracking age varies considerably, even between industrialized countries, the tracking is applied at ages of 15 or 16 in most Organisation for Economic Co-operation and Development (OECD) countries (Woessmann, 2009).

Therefore, the school tracking often leads to the constitution of rather homogenous student groups, but according to school types with different curricula. This thus leads to classes in which the students have almost the same achievement levels. In other words, the school tracking leads to grouping based on the previous performance, with higher achieving students being separated from lower achieving students (Brunello, 2004). The effects of an increase in the number of school types on students' academic performance and optimal tracking age are much discussed issues within scope of equality and efficiency in education (Brunello, 2004; Hanushek and Woessmann, 2006; Marks, 2006; Reichelt et al., 2019; Roemer, 1998; Woessmann, 2009; Zimmer, 2003).

Historically, source of differentiation via school tracking in education systems stemmed from the increase in demand of the labor markets towards vocationally skilled workers after industrial revolution (Bell, 1973; Davis and Moore, 1945). Since industrial revolution, labor market has remarkably changed, a great number of new occupations emerged and therefore, skills via general education have become insufficient. Education systems were restructured to gain students with demanded complex skills, resulted in a new type of schools called vocational track in addition to general or academic track (Benavot, 1983; Grubb, 1985). Increasing in the demand towards human resources with new skills have resulted in growing of vocational education and training (VET) to meet the manpower requirements (Trow, 1961). Therefore, the driving force of tendency towards VET in education systems is constituted by skill demands of the labor market caused by technological changes.

Before the establishment of VET institutions, vocational education was presented as apprenticeship programs with the support of craftsman and worker via artisanal and industrial trades union (Scott, 1914). On the one hand, including of VET to education systems led to weakening of union-controlled apprenticeship education; on the other hand, it led to raising of the disciplined manpower, which is appropriate for division of labor, empowering the national integration (Benavot, 1983).

It is also claimed that education tracking has a latent purpose of maintaining the social distance between social classes (Bowles and Gintis, 1976; Collins, 1979; Lucas, 1999; Marshall, 1950). Since the gap between well-educated elite class and less-educated lower classes was weakened after the expansion in education, it is expressed that educational tracking was structured to strengthen the gap (Bol and Van de Werfhorst, 2013a, 2013b). Bourdieu and Passeron (1990) emphasized that education provides an important instrument to maintain the current social classes within social structure. In other words, educational stratification continues its existence and provides the reproduction of social classes through the school tracking. In this context, ratio of VET to general education is considered as measure of social stratification (Bertocchi and Spagat, 2004).

Although the tracking is applied to separate a room for VET, the tracking is discussed in terms of advantages, as well as disadvantages for VET and equality in education and opportunity. The discussions about the impact of tracking focus on the tracking age, the percentage of curriculum differentiation, and the number of tracking schools (Reichelt et al., 2019). An early tracking makes the student's achievements much more dependent on their socioeconomic background (Marks, 2006; Reichelt et al., 2019). If the degree of curriculum differentiation is higher, and as such very specific to particular occupations, as for example in
Germany, then youth unemployment is lower and the school-towork time is shorter (Bol and Van de Werfhorst, 2013a, 2013b; Hanushek et al., 2011, 2017). However, graduates of VET have fewer chances for higher education and prestigious professions (Müller and Shavit, 1998). In addition, their mobility between occupations is also limited (Solga et al., 2014). Therefore, the tracking seems to provide a mechanism of social reproduction by diverting working-class students from higher education and prestigious professions, while at the same time locking them into a narrow occupational category (Shavit and Müller, 2000).

On the other hand, the vocational track does provide, or at least intends to provide, skill sets the labor market demands. If we leave this to machines, an automation procedure may spread in all the fields of everyday life and change working conditions and service experience, especially also in the light of evermore present artificial intelligence technologies (Perc et al., 2019). The new labor market dynamics demands some skill sets very fast by devaluating others, but also requiring ever new skills for new and emerging business lines and technologies (Acemoğlu and Restrepo, 2018). Therefore, beyond the school tracking and its effects, VET seems to be at a crossroads. In this context, some countries responded to this challenge by restructuring their VET systems in a more academic way, rather than vocationally, in particular by decreasing the degree of curriculum differentiation, allowing broader VET curricula, and by decreasing the number of training occupations (Solga et al., 2014).

At this point, the restructuring of VET systems thus requires taking into account both the school tracking and the new demands on VET. In this study, the effects of tracking are evaluated in the context of equality in education and opportunity. The impact of tracking on VET is also surveyed and suggestions for the restructuring of VET are presented in this context.

\section{Tracking and equality}

The degree of school tracking became a much discussed issue of educational systems all around the world in terms of its intended and unintended consequences (Bol and Van de Werfhorst, 2013a, 2013b; Brunello, 2004; Hanushek and Woessmann, 2006; Marks, 2006; Pekkarinen et al., 2006; Reichelt et al., 2019; Roemer, 1998; Woessmann, 2009; Zimmer, 2003). What is the long-term impact of educational tracking on equality in terms of education and opportunities later in life? An important argument in favor of school tracking is that it allows the specialized curriculum for homogenous classes (i.e., VET) and presents the convenience for maximum learning. Thus, it creates an opportunity to decrease the concerns of teachers for classes with both fast learning- and slow learning students (Hanushek and Woessmann, 2006). In other words, it seems easier for student groups with the same abilities to focus on certain learning goals and educational progress in the tracked systems (Jacobs and Wolbers, 2018). However, it is also expressed as an opposing view that tracking leads to systematic disadvantages for lower performing students who are already studying in environments, which do not promote learning sufficiently. In addition, the tracking in early ages increases the noise effect of tracking (risk of students' misclassification) (Brunello, 2004). When students are tracked earlier, students' performance becomes more dependent on their social background (Marks, 2006; Reichelt et al., 2019). Therefore, earlier tracking increases the risk of misallocating individuals to the tracks (Brunello, 2004).

When nonlinear peer effects are considered, heterogeneous classes lead to increase in efficiency, providing that lowperforming students have better opportunities to increase their performance via more effective group discussions and motivation based on interactions while high-performing students do not have 
any disadvantage (Hanushek and Woessmann, 2006). Thus, the tracking that leads to homogeneity may deprive of lowperforming students from these opportunities (Zimmer, 2003). Criticism about tracking in early ages mainly focus on systematic disadvantageous position of low-performing students in these conditions (Woessmann, 2009). Another common concern about the early tracking is an increase in inequality of opportunities because of that the lower ability students may be clustered in schools with lower level dominated by the family effects (Hanushek, 2019). Since they are clustered in lower tracks, they have fewer chance for attending university and finding more prestigious occupations (Müller and Shavit, 1998).

In this context, researchers studied the impact of the tracking age on inequality based on international large-scale student assessment data such as PISA, TIMSS, and PIRLS. Hanushek and Woessman (2006) studied the effects of early tracking on the students' performance and distributions based on the PISA, TIMSS, and PIRLS data and found that it increases the inequality in education. They compared the countries with different tracking ages and showed that countries with highest inequality between primary schools and high schools are the ones, in which the tracking is implemented in early ages. They also found that countries with lowest inequality between primary schools and high schools are the ones, in which the tracking is implemented later than the PISA sample age. In other words, educational inequality increases systematically in countries, which implement early tracking. It is also seen that Germany is the country with the highest increase in inequality, where also the tracking is implemented at a quite an early age (Woessmann, 2009).

On the other hand, it is known that family background is one of the most effective factors on students' academic achievement in both national and international studies (Woessmann, 2009). When it is considered that students' family- and socioeconomic backgrounds have significant impact on their academic achievement before the tracking, the inequality is still in existence even in primary education level. Therefore, the tracking that depends on students' academic performance even worsens the disadvantageous position of low-performing students' and systematically deepens the inequality. This inequality is generally named as an inequality of opportunity (Betts and Roemer, 2007; Roemer, 1998; Schuetz et al., 2008; Woessmann, 2009).

Schuetz et al. (2008) investigated the dependence of students' performance on family backgrounds and if there is systematically relationship with education policies of diverse countries, and found that inequality in opportunity decreases remarkably when the tracking age is delayed. In other words, when students are tracked earlier, students' performance become more dependent on their family background. Woessmann et al. (2009) focused on the relationship between the tracking and the equality in opportunity and showed that difference of students' performances from diverse socioeconomic backgrounds is quite large in countries with early tracking. Specific to Germany, the equality in opportunity for students from disadvantageous backgrounds is comparatively higher in states with less school types (Woessmann, 2009). Bol and Van de Werfhorst (2013a, 2013b) studied the effects of tracking on educational functions and showed that the effect of socioeconomic background on science test scores increases and equality in opportunity decreases if level of tracking in education system is increased.

Recent studies focus on the role of education in the context of social reproduction through the flow from social origin to destination, firstly expressed by Bourdieu (1973) (Bernardi and Ballarino, 2016; Breen and Jonsson, 2005; Breen, 2010; Reichelt et al., 2019). Since the degree of economic status' transferability within families through generations is considered as an important indicator, both intergenerational income mobility and intergenerational income correlations are investigated in these studies. For example, Dustmann (2004) showed that high intergenerational correlation in Germany is related with the early tracking. Meghir and Palme (2005) studied the impact of the comprehensive school reform in Sweden in 1950s' on the income of students from less-educated families, and found that it led to an increase in the intergenerational income mobility. Pekkarinen et al. (2006) investigated the impact of Finland's comprehensive schooling reform in 1970s' on intergenerational income mobility and found that the reform led to a $20 \%$ decrease in intergenerational income correlation. Two fundamental characteristics of Finland comprehensive schooling reform are the postponement of tracking age from 11 to 16 , and presenting the same curriculum, which is intensified with academic content, to all students until the age of 16 . It is considered that both characteristics played important roles to achieve that result. Postponement of tracking age leads to decrease the effect of family background on educational attainment and increases the education mobility, and thus, decreases the intergenerational income elasticity. Besides, academically intensified curriculum of the comprehensive education has a positive effect on lifetime income levels of students from lowincome families and thus, it leads to decrease in intergenerational income correlation (Pekkarinen et al., 2006).

Reichelt et al. (2019) studied the effect of school tracking on social reproduction via three indicators, i.e., the tracking age, the percentage of curriculum differentiation of tracked schools, and the number of tracking schools. Results showed that a decrease in the tracking age and an increase in the percentage of curriculum differentiation are related with greater educational inheritance and the number of tracking schools is related with direct effect of social origin. On one hand, the relationship between family education level and occupational status is positive and significant in all included countries, on the other hand, direct effects of educational inheritance and social origin become stronger if the tracking level is increased (Reichelt et al., 2019).

In addition, the tracking is also effective on the civic behaviors of citizens. Hyland (2006) showed that democratic attitudes are balanced in higher levels when the student composition in classes becomes more heterogeneous. Janmaat and Mons (2011) found that variation of civic competences increases in countries where the tracking exists. Bol and Van de Werfhorst (2013a, 2013b) studied the effects of tracking on educational functions and found that possibility of students to become active citizens decreases when the degree of tracking is increased. Therefore, the tracking also leads to downshift of active citizenship.

\section{Tracking and vocational education}

Apart from facilitating inequalities and unfair chances in life; if applied at too early stages of education, the tracking is supposed to have a favorable impact on vocational education in that it provides the workforce the market demands. However, is this truly the case? As we will argue in what follows, the tracking seems to have a negative impact on the quality of vocational education, because lower achieving students separated for vocational track cannot achieve the desired competencies that are increasingly needed to keep pace with technological innovations and high-end services.

Educational systems optimize the skills of students and prepare them for the labor market (Bol and Van de Werfhorst, 2013a, 2013b). The tracked students are often trained to gain skills for a working life. However, the level of vocational orientation may show remarkable alterations between countries. For instance, VET programs are generally presented in a number of broader fields and applied school-based way in most countries 
while, in some countries, VET is presented as dual system model, in which education and on-work trainings in companies are combined and specific skills towards workplaces are intensified (Bol and Van de Werfhorst, 2013a; Breen, 2005). Therefore, types and processes of VET differ across countries (Hanushek et al., 2011; Müller and Gangl, 2003; Müller and Shavit, 1998). In workbased VET systems, students gain specific skills towards workplaces while students gain more general skills in school-based VET systems (Bol and Van de Werfhorst, 2013a).

School tracking seems to have some advantages for the vocational track. It is found that the tracking has positive effects on the labor market allocation for VET graduates (Bol and Van de Werfhorst, 2013b). Results of international studies, which focus on students' academic achievement and literacy levels, are widely used to evaluate the readiness of graduates towards working life. In this context, a comparative analysis of general and VET programs is crucial for observing the indirect effects of the tracking. For instance, Hanushek et al. (2011, 2017) compared the employment status and salaries of VET and general education graduates based on the results from the OECD's International Adult Literacy Survey (IALS), allowing direct monitoring of cognitive skills in different age groups and school types. They found that VET graduates have the advantage in employability and income levels between 16- and 26-year-old. Bol and Van de Werfhorst (2013b) also showed that in countries where VEToriented tracking is implemented, youth unemployment is lower and the duration of the school-to-work transition is shorter. In this context, the German dual VET system has received praise for decades because of its beneficence for school-to-work transitions. Since it is actively embedded in the labor market structure and provides highly occupation-specific skills, the youth unemployment rate in Germany is low. For example, in 2012, 66\% of the apprenticeship graduates have been employed by the firm in which they were trained (Solga et al., 2014).

On the other hand, Hanushek et al. (2017) also showed that graduates of general education take the advantage in employability and income levels as age increases. In other words, VET graduates are employed at higher rates immediately after graduation with the support of workplace training, but vocational skills become insufficient against the skills requested by the labor market in later stages as age increases lead to a decrease in both employability and income level (Hanushek et al., 2017). This change is especially much more apparent in countries such as Germany where both the work-based vocational education model is predominantly applied and the tracking is implemented in quite early ages (Hanushek et al., 2011). Therefore, we may suggest that the early tracking does not bring any advantage for VET graduates in terms of life-long employability and income levels. Ironically, although the tracking is implemented for its own use, VET seems to be an education type, which is affected negatively by the tracking to great extent. In most OECD countries, VET is perceived as a low-status education type and it is mostly evaluated as a second- or third-choice (CEDEFOP 2018; Chong, 2014; Ozer, 2018; Ozer, 2019a; Ozer, 2019b; Sahlberg, 2007). VET also suffers from high school drop-out and absenteeism ratios (Abusland, 2014; CEDEFOP, 2018; EQAVET, 2015; Vantuch and Jelinkova, 2013; Waltzer and Bire, 2014). Generally, children of lower socioeconomic families or immigrant families are clustered in VET programs (Ozer et al., 2011; Ozer, 2019b).

The value of skills gained in VET decreases faster in response to the rapid technological changes, leading to those vocational skills becoming insufficient and indeed not needed by the labor market as age increases (Hanushek et al. 2017). Since the skills of VET graduates become useless due to the dynamic structure of the labor market, and this especially so in fast growing economies, this also leads to increased investment costs of life-long learning at later stages (Hanushek, 2012). Moreover, since skills attained in general education facilitate adapting to technological transformation, this allows general education graduates to have better long-term employment opportunities. In other words, although general education has no immediate connection with a particular occupation, it provides more general and versatile skills that can be used to learn different occupations later in life (Brunello, 2004).

\section{The Matthew effect}

Although not featuring prominently in the existing literature on educational tracking, we nevertheless feel that the Matthew effect is crucial for understanding, and even for actually explaining, many of the long-term negative consequences of tracking (Perc, 2014). The Matthew effect posits that success breeds success, or that rich get richer. It has also been referred to as cumulative advantage, and as preferential attachment, all describing the fact that advantage tends to beget further advantage. In the realm of education, it simply means that those students who start well will finish even better in comparison to those who start poorly. Evidently, if educational tracking is applied early on, those who are initially downgraded, or perform poorly due to other socioeconomic factors, have an inherent disadvantage that gets more and more difficult to remedy as time goes by.

The Matthew effect was first made popular by the sociologist Robert K. Merton (1968), who took inspiration from the Gospel of St. Matthew, where it says "For to all those who have, more will be given". Merton then used the phrase the Matthew effect to explain the discrepancies in recognition received by eminent scientists and unknown researchers for much the same work. However, already a few years earlier physicist Derek J. de Solla Price (1965) observed a similar phenomenon when studying the network of citations between scientific papers, only that he used the phrase cumulative advantage for the description. The concept today is in use to describe the general pattern of self-reinforcing inequality related to economic wealth, political power, prestige, knowledge, and in fact education (Rigney, 2013). The Matthew effect also contributes to a number of other phenomena in the social sciences that may be broadly characterized as social spirals. Examples include inflationary spirals, spiraling unemployment, and spiraling debt. These spirals exemplify positive feedback loops, in which processes feed upon themselves in such a way as to cause nonlinear patterns of growth, as illustrated in Fig. 1.

An insightful synthesis titled "Matthew effects in reading: Some consequences of individual differences in the acquisition of literacy" is due to Stanovich (2008), where a framework is presented for conceptualizing the development of individual differences in reading ability, with special emphasis on the concepts of reciprocal relationships. Foremost, it is explained how these mechanisms operate to create the rich-get-richer and the poorget-poorer patterns of reading achievement, and the framework is used to explicate some persisting problems in the literature on reading disability and to conceptualize remediation efforts in reading. It is emphasized that due to the Matthew effect, early deficiencies in literacy may bread life-long problems in learning new skills, and falling behind during formative primary school years may create disadvantages that could be difficult to compensate all the way to adulthood (Stanovich, 2008).

According to the Matthew effect, and based on troves of folktales, and based also on data on the social capital hypothesis and social networks, being born into poverty greatly increases the probability of remaining poor, and each further disadvantage makes it increasingly difficult to escape the economic undertow. The same applies to education, and educational tracking to less demanding programs based on poor early performance essentially 


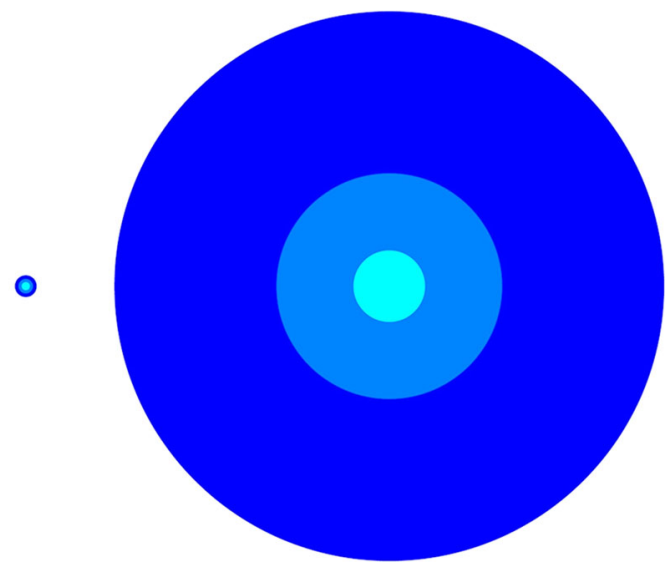

Fig. 1 An illustration of self-reinforced nonlinear growth. We start on the left hand side with three barely visible circles. The blue circle has diameter 5, light-blue circle has diameter 4, and the cyan circle has diameter 3 (at this point, the colors are not distinguishable because the sizes of these circles are too small). If we assume the growth is proportional with the size, during each time step the circles become larger by a factor equivalent to their current diameter. After the first time step, shown in the middle, this gives us circles of sizes 25,16 , and 9 , respectively. Continuing at the same rate, after the second time step shown on the right hand side, we have sizes 625,256 , and 81 . Clearly, such a procedure quickly spirals out of easily imaginable bounds. In this example, the diameter of the circles can represent anything, from the amount of money one owns to literacy during formative years. The key message is that even tiny differences at early stages grow out of proportions fast if proper precautions are not taken. Educational tracking can easily contribute to exacerbating very small differences in early school performance to life-changing proportions.

shuts many doors that would remain open were it not for the selection. Accordingly, in the light of these information and statistical data on the performance of educational tracking, it is at the very least strongly advisable that tracking be postponed to much later in life, and then also with ample options to revert to other tracks as needed.

\section{Discussion}

Although the school tracking may bring short-term advantages for VET graduates, our review shows that it also increases the inequality in education and opportunity. Negative effects of tracking become especially obvious when the tracking is implemented in early ages, and this simply because of the fact that the impact of the socioeconomic background is then often too decisive and determinant. So who are those that get the best of tracking in early ages? Hanushek and Woessman (2006) found that both low-performing students and high-performing students suffer from the early tracking, and no one gets more at the expense of the others. On the other hand, students from lowsocioeconomic backgrounds perform higher and students from high socioeconomic backgrounds perform at similar levels if the tracking age is delayed (Woessmann, 2009; Woessmann et al., 2009).

The school tracking is also related with inequality in the labor market in the long-term. It is shown that there is a close relationship between income inequality and inequality in educational performance (Woessmann, 2009). Students from disadvantageous backgrounds are mostly clustered in lower levels and thus, they have lower chances to get into university and prestigious occupations (Müller and Shavit, 1998; Reichelt et al., 2019). Nickell (2004) showed that majority of international differences in income inequality can be dedicated to international differences of inequality in educational achievement, which can be evaluated via international academic achievement and literacy studies. Retarding of the tracking age also decreases the inequalities, which can be occurred in labor market in a long-term (Meghir and Palme, 2005; Pekkarinen et al., 2006; Woessmann, 2009).

Reforms in education systems to minimize the effect of tracking focus on the delaying of the tracking age, maintaining the comprehensive education and presenting same curriculum to all students until the tracking age (Meghir and Palme, 2005; Pekkarinen et al., 2006). By this way, it is intended to decrease both inequality in education and inequality in opportunity. Consequently, under the assumption that socioeconomic differences and disadvantageous backgrounds will continue their existence, it is essential that education systems need to focus on the comprehensive education rather than tracking as much as possible in order to ensure equality in education and opportunity.

On the other hand, since the school tracking will allow the implementing of vocational curriculums in schools, delaying of school tracking to later ages will increase the equality in opportunity without any cost totally. At this juncture, the percentage of curriculum differentiation is critical. Especially, reducing the percentage as much as possible has a potential to minimize the negative effects since the current situation of labor market gives an opportunity for this transformation in VET.

Nowadays, automation has become widespread and supported by artificial intelligence technologies all over the world, thus challenging and changing the labor market and its dynamics (Perc et al., 2019). The labor market regulates skill demands more dynamically through devaluating some skills while bringing new skills to the fore. This transformation, which is dominated by automation and artificial intelligence, has led on one hand to a negative effect on employment (displacement effect) but on the other hand to new skills for new business lines (Acemoğlu and Restrepo, 2018). If the VET does not supply enough skills dynamically in response to dynamic change in skills demand, there may be shortages in one sector and oversupply in other sectors, ultimately resulting in a mismatch in the labor market (Johansen and Gatelli, 2012). This skill mismatch eventually increases the risk in employability and/or leading to an increased employment for low-skilled jobs. When the training of VET students is closely linked to occupation-specific skills, as in Germany, it results in a decrease in the occupational mobility of the graduates on one hand, and an increase in the risk of unemployment or employment only in low-skilled jobs in the long-term on the other hand. In other words, although the high degree of occupational specificity in Germany facilitates the school-to-work transition, it limits horizontal and upward occupational mobility. Therefore, those who have to leave their initial occupation for some reason are exposed to higher risks of unemployment and downward mobility such as semi- or lowskilled jobs (Solga et al., 2014). In addition, in Germany, since the VET curriculum is revised in a consensual manner by representatives of the federal government, state governments, chambers, trade unions and experts, it takes many years to do so (Solga et al., 2014). Therefore, the employability advantage of VET graduates in Germany decreases as age increases (Hanushek et al., 2017). On the other hand, since the dual VET system includes the students from early tracking, it has also been criticized for channeling working-class children into the VET track and diverting them from entering higher education (Mayer et al., 2007; Powell and Solga, 2011; Shavit and Müller, 2000; Solga et al., 2014).

In countries with a stronger emphasis on vocational education in the form of a dual system, since students are prepared for a more specific job in the occupational structure, young employees 
spent more time in the same job (Bol and Van de Werfhorst, 2013b). New conditions make the restructuring of VET inevitable in line with the new dynamics of the labor market. One clear implication of the new market is the relative demand shift toward more general and versatile skills (Brunello, 2004). In addition, flexible mobility between professions and the strengthening of general and versatile skills must likewise be an integral characteristic of the new VET structure (Brunello, 2004; Sahlberg, 2007). Since the general track appreciates more general and versatile skills, graduates of general education tracks get ahead of the VET graduates in employability advantage as age increases (Hanushek et al., 2017). Therefore, Germany for example, seeks an efficient way to restructure its VET system. In this context, a new hybrid form of a dual system has emerged recently as a joint initiative with large firms, which allows both a vocational certificate and a bachelor's degree (Solga et al., 2014). Furthermore, in order to prevent overspecialization in VET and facilitate the mobility especially in later work life, a broader definition of occupations, a lower degree of occupational specificity, and a lower number of training occupations have all been proposed (Müller and Shavit, 1998). Accordingly, Denmark also revised its dual VET system by reducing the duration of workplace training, by decreasing the degree of curriculum standardization, by allowing more broad-based curricula, and by decreasing the number of training occupations (Solga et al., 2014).

Countries that consider VET as a career path where academic skills can be gained only to a limited extent may push themselves into a disadvantageous position in the long-term development process (Hanushek, 2012). At the moment, the skills gained through VET are not alternatives for general skills; on the contrary, they become an integral part of general skills. In this context, restructuring in VET requires both simplifying VET fields and branches and increasing the share of general and versatile skills to increase the life-long employability in response to the new labor market (Ozer, 2019b). Therefore, in order to meet the demands of new labor market, restructuring of VET, in such a way that will gain students to broader skills instead of specific skills peculiar to certain occupations, allow students for flexible transitions between occupations and motivate them to gain general skills, will empower the resilience of VET graduates and increase the life-long employability of them.

After the industrial revolution, the ratio of VET in general education increased. However, this increase came to a top in 1950s' while later this ratio began to decrease (Benavot, 1983). When the ratio of VET to general education is considered as an indicator of social stratification (Bertocchi and Spagat, 2004), this reduction means a relative decrease in the social stratification. The later tracking also decreases the inequalities in the labor market, especially in the long-term (Meghir and Palme, 2005; Pekkarinen et al., 2006; Woessmann, 2009). Besides, new transformation of VET, demanded by the labor market, will decrease the percentage of curriculum differentiation in VET. Both characteristics of this new trend will eventually decrease the inequality in education and opportunities. The rise of VET after the industrial revolution is explicitly related with supply for the demands of the labor market and the maintenance of the status' of social classes in a society in a latent complex manner. The restructuring of VET, supported by new characteristics of the labor market, is thus related not only with the changing needs of this market, but also with the increased equality in education and job opportunities later in life.

Received: 19 October 2019; Accepted: 12 February 2020; Published online: 28 February 2020

\section{References}

Abusland T (2014) Early leaving from vocational education and training: United Kingdom. UK NARIC, ECCTIS, UK

Acemoğlu D, Restrepo P (2018) Artificial intelligence, automation and work. NBER Working Paper 24196. National Bureau of Economic Research, Cambridge

Bell D (1973) The coming of post-industrial society. Basic Books, New York, NY

Benavot A (1983) The rise and decline of vocational education. Sociol Educ 56:63-76

Bernardi F, Ballarino G (2016) Education, occupation and social origin: a comparative analysis of the transmission of socio-economic inequalities. Edwarg Elgar, Cheltenham

Bertocchi G, Spagat M (2004) The evolution of modern educational systems: technical vs. general education, distributional conflict, and growth. J Dev Econ 73:559-582

Betts P, Roemer JE (2007) Equalizing opportunity for racial and socioeconomic groups in the United States through educational-finance reform. In: Woessmann L, Peterson PE (eds) Schools and the equal opportunity problem. MIT Press, Cambridge, pp 209-237

Bol T, Van de Werfhorst HG (2013a) The measurement of tracking, vocational orientation, and standardization of educational systems: a comparative approach. GINI Discussion Paper 81:1-42

Bol T, Van de Werfhorst HG (2013b) Educational systems and the trade-off between labor market allocation and equality of educational opportunity. Comp Educ Rev 57(2):285-308

Bourdieu P (1973) Cultural reproduction and social reproduction. In: Brown RK (ed) Knowledge, educational and cultural change. Tavistock, London, pp. 71-112

Bourdieu P, Passeron JC (1990) Reproduction in education, society and culture. Sage Publications, London

Bowles S, Gintis H (1976) Schooling in capitalist America educational reform and the contradictions of economic life. Basic Books, A Division of HarperCollins Publishers, USA

Brunello G (2004) Stratified or comprehensive? Some economic considerations on the design of secondary education. CESifo DICE Rep 4:7-10

Breen R (2005) Explaining cross-national variation in youth unemployment: market and institutional factors. Eur Sociological Rev 21:125-134

Breen R (2010) Educational expansion and social mobility in the 20th century. Soc Forces 89(2):365-388

Breen R, Jonsson JO (2005) Inequality of opportunity in comparative perspective: recent research on educational attainment and social mobility. Annu Rev Sociol 31:223-243

Chong T (2014) Vocational education in Singapore: meritocracy and hidden narratives. Discourse: Stud Cultural Politics Educ 35(5):637-648

Collins R (1979) The credential society: an historical sociology of education and stratification. Academic Press, New York, NY

Davis K, Moore WE (1945) Some principles of stratification. Am Sociological Rev 10:242-249

de Solla Price DJ (1965) Networks of scientific papers. Science 149:510-515

Dustmann C (2004) Parental background, secondary school track choice, and wages. Oxf Economic Pap 56:209-230

CEDEFOP (2018) The changing nature and role of vocational education and training in Europe, Vol. 3: The responsiveness of European VET systems to external change (1995-2015). Cedefop Research Paper 67. Author, Luxemburg

EQAVET (2015) Actions to reduce early leaving in vocational education and training. EQAVET Policy Brief. Council of the European Union Publishing, Brussels, Belgium

Grubb WN (1985) The convergence of educational systems and the role of vocationalism. Comp Educ Rev 29:526-548

Hanushek EA, Woessmann L (2006) Does educational tracking affect performance and inequality? Differences-in-differences evidence across countries. Economic J 116:63-76

Hanushek EA (2012) Dual education: Europe's secret recipe? CESifo. Forum 13 (3):29-34

Hanushek EA, Schwerdt G, Woessman L, Zhang L (2017) General education, vocational education, and labor-market outcomes over the life-cycle. J Hum Resour 52(1):48-87

Hanushek EA, Woessman L, Zhang L (2011) General education, vocational education, and labor-market outcomes over the life-cycle. NBER Working Paper 17504. National Bureau of Economic Research, Cambridge

Hanushek EA (2019) Addressing cross-national generalizability in educational impact evaluation. NBER Working Paper 25460. National Bureau of Economic Research, Cambridge

Hyland NE (2006) Detracking in the social studies: a path to a more democratic education? Theory into Pract 45:64-71

Jacobs B, Wolbers MHJ (2018) Inequality in top performance: an examination of cross-country variation in excellence gaps across different levels of parental socioeconomic status. Educ Res Evaluation 24:68-87 
Janmaat JG, Mons N (2011) Promoting ethnic tolerance and patriotism: the role of education system characteristics. Comp Educ Rev 55:56-81

Johansen J, Gatelli D (2012) Measuring mismatch in ETF partner countries: a methodological note. European Training Foundation (ETF), Torino, Italy

Lucas SR (1999) Tracking inequality: stratification and mobility in American high schools. Teachers College Press, New York, NY

Marks GN (2006) Are between-and within-school differences in student performance largely due to socioeconomic background? Evidence from 30 countries. Educ Res 48(1):21-40

Marshall TH (1950) Citizenship and social class and other essays. Cambridge University Press, Cambridge

Mayer KU, Müller W, Pollak R (2007) Germany: Institutional change and inequalities of access in higher education. In: Shavit Y, Arum R, Gamoran A (eds.) Stratification in Higher Education. Stanford University Press, Stanford, pp 240-265

Meghir C, Palme M (2005) Educational reform, ability, and family background. Am Economic Rev 95(1):414-424

Merton RK (1968) The Matthew effect in science. Science 159:53-63

Müller W, Shavit Y (1998) The institutional embeddedness of the stratification process. A comparative study of qualifications and occupations in thirteen countries. In: Shavit Y, Müller W (eds) From school to work. A comparative study of educational qualifications and occupational destinations. Clarendon Press, Oxford, pp 1-47

Müller W, Gangl M (2003) Transitions from education to work in Europe. Oxford University Press, Oxford/NY

Nickell S (2004) Poverty and worklessness in Britain. Economic Journal 114(494): $\mathrm{C} 1-\mathrm{C} 25$

Ozer M (2018) The 2023 education vision and new goals in vocational and technical education (In Turkish). J High Educ Sci 8(3):425-435

Ozer M (2019a) Background of problems in vocational education and training and its road map to solution in Turkey's education vision 2023 (In Turkish). J High Educ Sci 9(1):1-11

Ozer M (2019b) Reconsidering the fundamental problems of vocational education and training in Turkey and proposed solutions for restructuring. İstanbul Üniversitesi Sosyol Derg 39(2):1-19

Ozer M, Çavuşoğlu A, Gür BS (2011) Restoration and recovery period: 2000s in vocational and technical education (In Turkish). In: Gür BS (ed) 2000s: Education in Turkey. Meydan, İstanbul, pp 163-192

Perc M (2014) The Matthew effect in empirical data. J R Soc Interface 11:20140378

Perc M, Ozer M, Hojnik J (2019) Social and juristic challenges of artificial intelligence. Palgrave Commun 5:61

Pekkarinen T, Uusitalo R, Pekkala S (2006) Education policy and intergenerational income mobility: evidence from the Finnish comprehensive school reform. IZA Discussion Paper 2204, Institute for the Study of Labor, Bonn

Powell JJW, Solga H (2011) Why are participation rates in higher education in Germany so low? Institutional barriers to higher education expansion. J Educ Work 24(1):49-68

Reichelt M, Collischon M, Eberl A (2019) School tracking and its role in social reproduction: reinforcing educational inheritance and the direct effects of social origin. Br J Sociol 70(4):1-26

Rigney D (2013) The Matthew effect: how advantage begets further advantage. Columbia University Press, New York, NY

Roemer JE (1998) Equality of opportunity. Harvard University Press, Cambridge

Sahlberg P (2007) Secondary education in OECD countries: common challenges, differing solutions. European Training Foundation, Torino, Italy

Shavit Y, Müller W (2000) Vocational secondary education: where diversion and where safety net? Eur Societies 2(1):29-50
Schuetz G, Ursprung HW, Woessmann L (2008) Education policy and equality of opportunity. Kyklos 61(2):279-308

Scott JF (1914) Historical essays on apprenticeship and vocational education. Ann Arbor Press, Ann Arbor

Solga, H, Protsch P, Ebner C, Brzinsky-Fay C (2014) The German vocational education and training system: its institutional configuration, strength, and challenges. WZB Discussion Paper SP-I-2014-502

Stanovich KE (2008) Matthew effects in reading: some consequences of individual differences in the acquisition of literacy. J Educ 189:23-55

Trow M (1961) The second transformation of American secondary education. Int J Comp Sociol 2:144-166

Vantuch J, Jelinkova D (2013) Early leaving from vocational education and training in Slovakia. SIOV/SNO, Publications Office, Bratislava

Waltzer L, Bire M (2014) Early leaving from vocational education and training: Luxembourg. INFPC, Luxembourg

Woessmann L, Luedemann E, Schuetz G, West MR (2009) School accountability, autonomy and choice around the world. Edward Elgar, Cheltenham

Woessmann L (2009) International evidence on school tracking: a review. CESifo DICE Rep 1:26-34

Zimmer R (2003) A new twist in the educational tracking debate. Econ Educ Rev 22(3):307-315

\section{Acknowledgements}

M.P. was supported by the Slovenian Research Agency (Grant Nos. J4-9302, J1-9112, and P1-0403).

\section{Competing interests}

The authors declare no competing interests.

\section{Additional information}

Correspondence and requests for materials should be addressed to M.P.

Reprints and permission information is available at http://www.nature.com/reprints

Publisher's note Springer Nature remains neutral with regard to jurisdictional claims in published maps and institutional affiliations.

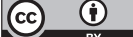

Open Access This article is licensed under a Creative Commons Attribution 4.0 International License, which permits use, sharing, adaptation, distribution and reproduction in any medium or format, as long as you give appropriate credit to the original author(s) and the source, provide a link to the Creative Commons license, and indicate if changes were made. The images or other third party material in this article are included in the article's Creative Commons license, unless indicated otherwise in a credit line to the material. If material is not included in the article's Creative Commons license and your intended use is not permitted by statutory regulation or exceeds the permitted use, you will need to obtain permission directly from the copyright holder. To view a copy of this license, visit http://creativecommons.org/ licenses/by/4.0/

(C) The Author(s) 2020 